\title{
A Real Time Data Monitoring System for Two- Degree of Freedom of Microcontroller based Solar Tracking System
}

\author{
M.V.Suparmaniam ${ }^{1, *}, V$. Sathis $^{1}$, and A.O. Arshed ${ }^{1}$ \\ ${ }^{1}$ Faculty of Manufacturing Engineering, Universiti Malaysia Pahang, 26600 Pekan, Pahang, Malaysia.
}

\begin{abstract}
The dual axis solar tracker was designed for optimum solar cell implementation using dc-dc boost converter which controlled by fuzzy logic controller with the maximum power point tracking (MPPT) method. The objectives of this project are to track and optimize the maximum output power of the solar panel by designing and implementing the fuzzy logic controller using microcontroller as well as to regulate the output voltage of the solar panel using dc-dc boost converter. The photocell panel will detect the existing of sun and the surface plate of photocell panel will move horizontal and vertical axis depending on the value of LDR detected to follow the angular degree of sun in order to get maximum and best result of absorbing energy. The result obtained from the Arduino coding is the variation of duty cycle of PWM signal according to the voltage of solar panel. The final result obtained from dc-dc boost converter showed that the output voltage has been regulated. Data Acquisition System is done by using Arduino voltage sensor and current sensor to collect data for each second with the real time data graph. Overall, the designed system increases the efficiency of the solar panel based on experimental results.
\end{abstract}

\section{Introduction}

Recently, solar energy has given more and more attention, it is a clean and renewable energy sources. The Photovoltaic (PV) cells are attained to convert solar energy from the sunlight directly to electrical energy. This energy can be utilized in many applications, like lighting, heating and performing different devices [1]. The sun powered cell is containing semiconductor physical which utilizing the photovoltaic impact. At the point when the daylight is opposite to exterior of the PV sun powered board, can acquire higher efficient system; therefore, maximum potential electrical energy can be established [1,2]. Much experimentation has been done to boost the efficiency of the solar cell. Few decades ago, solar cell modules have been created and have been invented by arranging in series to optimise the output voltage. Solar tracking system categorizes as a control system that consists of sensors to detect either the sunlight is upright to the PV panel or not, and a controller that deliver signals to one or more actuator for changing the panel to the maximum

* Corresponding author: arseed@ump.edu.my 
targeted position. Nowadays dual axis solar tracker mechanism gained interest in R\&D field due to the evidence of gain at the efficiency of the PV panel.

In the literature, different designs for solar tracking have been discussed. For the reduction of tracking time, fuzzy logic control algorithm is implemented with the embedded microcontroller for improved performance as compared to conventional techniques in power efficiency and swift maximum power point tracking [2]. The controller aims at maximizing the solar PV cell's efficiency by forcing sunlight to be incident perpendicularly to the PV panel at all times. The system consists of PV solar panel that is allowed to move using two motors, four PV sensors positioned at four different locations, and a fuzzy logic controller that takes the inputs from the four sensors and calculates the appropriate output speeds for both motors.
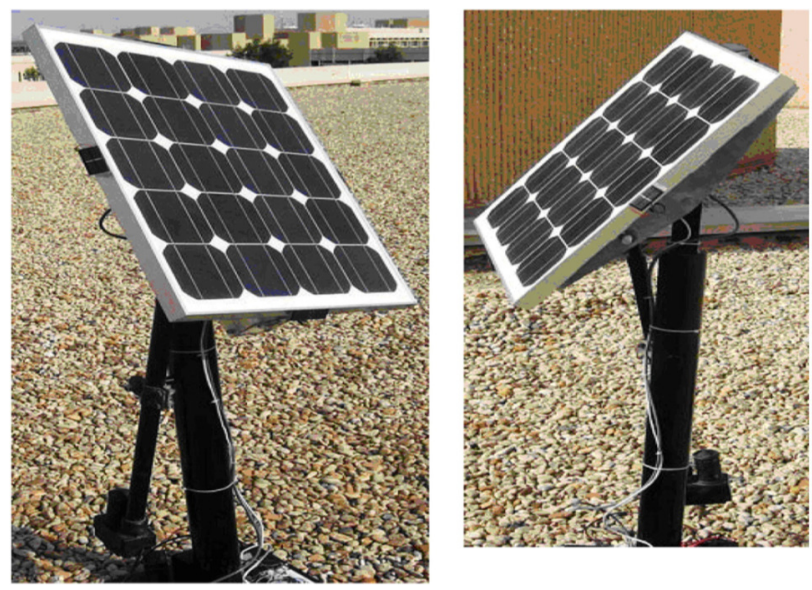

Fig. 1. Solar tracking system.

In [3] the author presented fuzzy control method for maximum power point tracking (MPPT) of photovoltaic (PV) system under varying irradiation and temperature conditions. The fuzzy control method has been compared with perturb and observe (P\&O) method as one of the most widely conventional method used in this area because of its simple and easily implementation. Fuzzy techniques give better and more reliable control and improve energy conversion efficiency for this application. In [4], the authors developed a small power photovoltaic control system based on fuzzy control with FPGA technology design and implementation for MPPT. The system composed of photovoltaic module, buck converter and the fuzzy logic controller implemented on FPGA for controlling on/off time of MOSFET switch of a buck converter. Simulation and experimental results show that performance of the fuzzy controller with FPGA in a maximum power tracking of a photovoltaic array can be made use of in several photovoltaic products and obtain satisfied result.

In $[5,7]$ authors implemented the fuzzy logic control based solar tracking system using Arduino Uno. Stepper motor helps in tracking the axis of the sun and keeps the panel in direction of the sun all day long and a Buck DC-DC Converter has been used for Maximum Power Point Tracking. The proposed fuzzy logic controller has been implemented and tested using MATLAB. The above sun tracking power generation system has been tested in real time using Arduino Uno. The designed system increases the energy generation efficiency of the solar cells. Developed process to track the sun and attain maximum efficiency using Arduino uno and LabVIEW for real time monitoring. In hardware development, four light dependent resistor (LDR) has been used for capturing maximum light source [6]. Two DC motors have been used to move the solar panel at maximum light source location sensing by 
LDR. The GUI is constructed by using LabVIEW. Data collected through the monitoring system will be analysed to identify the features of the effective solar system.
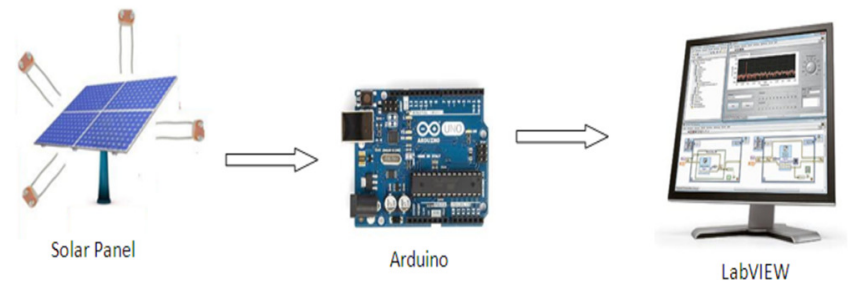

Fig. 2. Block diagram of system.

In this paper an intelligent fuzzy based tracking controller is introduced. The tracking system consists of a photovoltaic (PV) panel that can be positioned using two actuators. The controller depends on the output of the photovoltaic cells that acts as sensors fixed on the panel. The controller receives inputs from these sensors and performs continuous tracking throughout the daylight in order to maximize the efficiency of the PV solar panel. A simulation study is also performed.

\section{Design analysis of two axis sun tracking PV module}

The objective is to design a model prototype and test dual axis rotation sun tracking system for solar panel. In order to start a design, a basic design concept and draft the design out. The figure 3 is the draft design; it consists a PV solar panel, support of four aluminium profile and connected to an aluminium rod that allow the PV solar panel to rotate freely

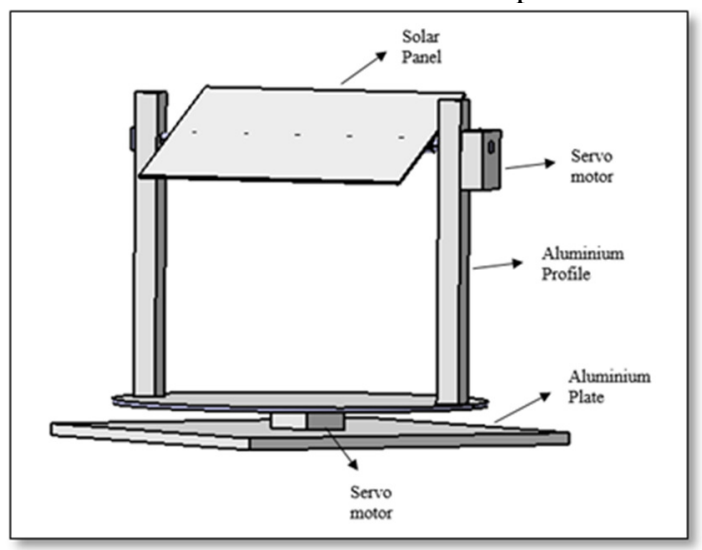

Fig. 3. Model prototype of dual axis solar tracker system.

The complete circuit for dual axis solar tracker system are designed in fritzing software. The components include in software are Arduino Uno, LDR, LED, servo motor, resistors, potentiometer and inductor. This model will track the sun concurring the light force of the LDRs and pivot from 180 degrees East to West and North to South. An active type of tracking system was used to track the position of sunlight in this project which included a microcontroller. The system was designed to track the sun position by detecting the analog signal of LDRs. The motor 1 will rotate clockwise if the analog signal of LDR 1 is detect and motor 1 will rotate counter clockwise if the analog signal of LDR 3 is detect. The motor 2 will rotate clockwise if the analog signal of LDR 2 is detect and will rotate counter clockwise if the analog signal of LDR 4 is detect. The following figure 4 is the flow chart of the model. 


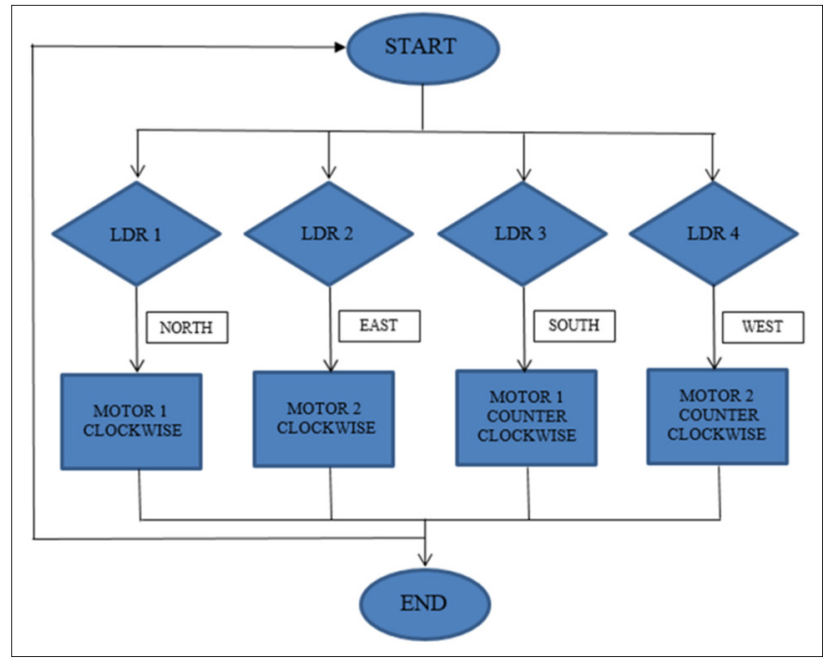

Fig. 4. Flow chart of design prototype.

\section{Design of Fuzzy Controller}

In this paper fuzzy logic controller will be used to control the two motors that move the PV panel in order to force it to be perpendicular to the sunlight all the time. The fuzzy logic control encloses three groups of principle work which are fuzzification, inference mechanism and defuzzification. This FLC utilizes the Mamdani technique which is generally acknowledged for catching master learning in fluffy tenets. It permits client to depict the ability in a human-like way not at all like the Sugeno strategy which is computationally compiling and works with streamlining and versatile strategies. The following flowchart shows the full process of fuzzy logic controller.
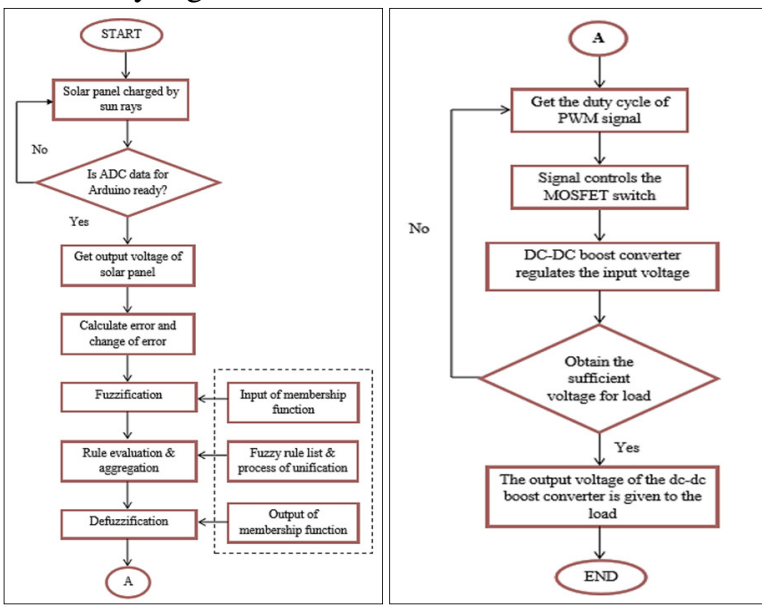

Fig. 5. Flowchart of process for complete system.

\subsection{Fuzzification}

The fuzzification is to convert the crisp inputs into the linguistic variables by means of fuzzy subsets. In this manner, the participation capacity qualities are communicated by phonetic variables utilizing fluffy subsets which are $\mathrm{Z}$ (zero), $\mathrm{P}$ (positive) and $\mathrm{N}$ (negative). A voltage 
of reference is altered and the yield voltage of the sunlight based board is computed by FLC. The error, E and the change of error, $\mathrm{CE}$ are ascertained utilizing the voltage of reference and yield voltage of sun powered board.

The initial values of FLC are E and CE also depend on numeral changeable that have their scope of qualities and are utilized to adjust the fluffy parameter to enhance the framework operation. This $\mathrm{E}$ worth is standardized by and data scaling variable such that the info qualities are at intervals of -1 to 1 . The preferred equation for calculating of $\mathrm{E}$ and $\mathrm{CE}$ as per the following:

$$
\begin{aligned}
& \text { Error }=V_{R E F}-V_{P V} \\
& \text { Change of Error }=\mathrm{E}(\mathrm{h})-\mathrm{E}(\mathrm{h}-1)
\end{aligned}
$$

where $V_{R E F}$ and $V_{P V}$ are the voltage of reference and yield voltage of photovoltaic panel appropriately. At the same time, $\mathrm{E}(\mathrm{h})$ and $\mathrm{E}(\mathrm{h}-1)$ are error values at the moment $(\mathrm{h})$ and (h-1).

\subsection{Inference Mechanism}

Fuzzy inference can be characterized as a procedure of mapping from the initial value to a yield which is utilizing the fluffy sets hypothesis. Principle assessment and conglomeration of the guideline yields incorporated into the fluffy deduction too. Guideline base has been composed with the fluffy subsets. The fluffy control is executed with the triangular participation capacities. The obligation cycle has been altered by yield voltage of the sun oriented board. For example, if the error and change of error is positive, it means the output voltage of solar panel is low. In this manner, the duty cycle must be expanded to get a most extreme voltage. The complete principle base can be found in the Table 1 beneath.

Table 1. Rule source

\begin{tabular}{|c|c|c|c|}
\hline $\mathrm{E}$ & $\mathrm{N}$ & $\mathrm{Z}$ & $\mathrm{P}$ \\
\hline $\mathrm{N}$ & $\mathrm{N}$ & $\mathrm{N}$ & $\mathrm{Z}$ \\
\hline $\mathrm{Z}$ & $\mathrm{N}$ & $\mathrm{Z}$ & $\mathrm{P}$ \\
\hline $\mathrm{P}$ & $\mathrm{Z}$ & $\mathrm{P}$ & $\mathrm{P}$ \\
\hline
\end{tabular}

Enrolment elements of inputs, error (E) and change of error (CE) and the output, duty cycle (D) are as take after.

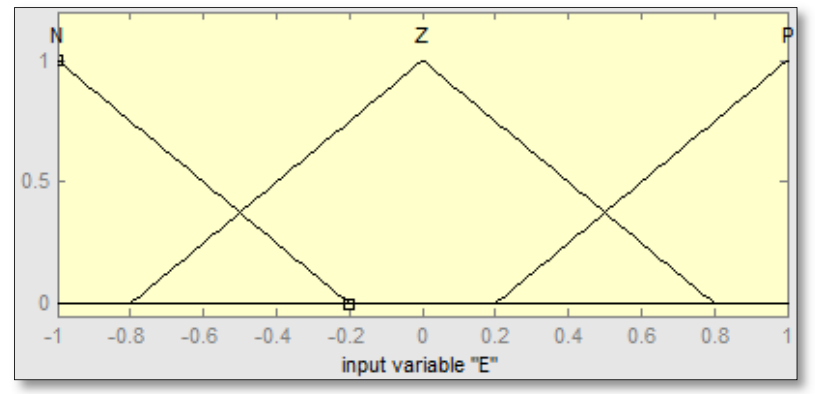

Fig. 6. Error,E. 


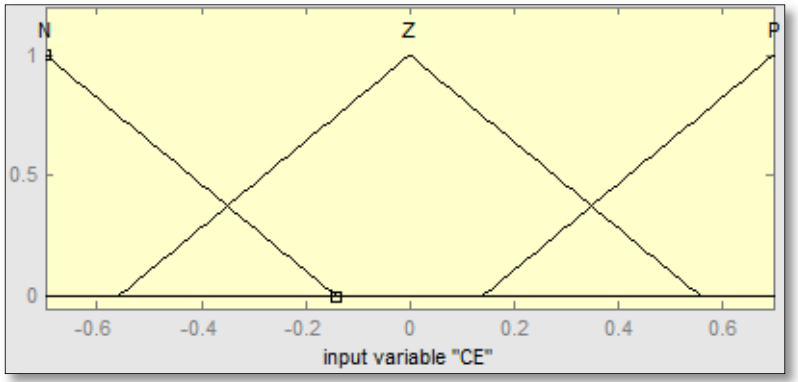

Fig. 7. Change of error, CE.

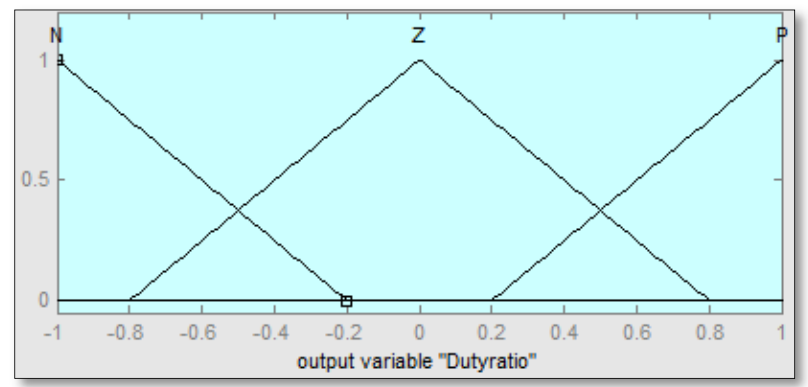

Fig. 8. Duty ratio, D.

The Figure 9 below displays the viewer of surface of the enrolment elements.

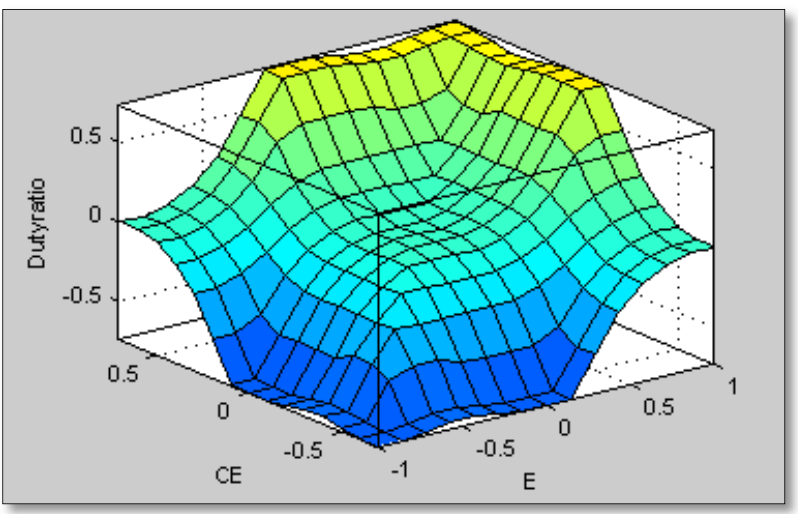

Fig. 9. Suface viewer

\subsection{Defuzzification}

The defuzzification changes over the surmising system into the genuine yield which is crisp number with the procedure. Mamdani strategy is been actualized in the observation that can be created by the centroid technique. The yield of fluffy rationale controller and duty ratio, $\mathrm{D}$ is contrasted with waveform of sawtooth to create a pulse for switch of MOSFET in dc-dc support converter. 


\subsection{Hardware Implementation}

\subsubsection{Arduino Voltage Sensor}

This module is based on the design principles of the resistor divider, enabling the terminal interface input voltage narrow five times, Arduino analogue input voltage up to $5 \mathrm{~V}$, then the input voltage of the voltage detection module cannot be greater than $5 \mathrm{~V} \times 5=25 \mathrm{~V}(3.3 \mathrm{~V}$ if used system, the input voltage cannot exceed $3.3 \mathrm{Vx} 5=16.5 \mathrm{~V})$. Because Arduino AVR chips used in $10 \mathrm{AD}$, so the simulation resolution of this module is $0.00489 \mathrm{~V}(5 \mathrm{~V} / 1023)$, so the minimum input voltage detection module detects voltage $0.00489 \mathrm{~V} \times 5=0.02445 \mathrm{~V}$.

\subsubsection{Arduino Current Sensor}

The ACS712 Current Sensor Module is a simple sensor that gives exact estimation of AC and DC streams. Current sensors are utilized to screen the measure of force or a torque. This present sensor module can deal with AC or DC streams up to 5A. A solitary simple yield signal interfaces with your microcontroller to give the sensor readings. This module works at $5 \mathrm{~V}$.

\subsubsection{Voltage Divider}

A potential divider is otherwise called a voltage divider. This is a direct circuit which delivers a yield voltage that is a small amount of its data voltage. Voltage division allowed to the gain of a potential difference among the divider segments. The division of voltage is ordinarily used to make a voltage of reference or to obtain a small voltage signal relative to the measured voltage. Furthermore, a voltage divider may be sufficiently accurate if made with only resistors for direct current and relatively low frequencies. The relation between the input voltage and yield voltage can be constructing by implementing Ohm's Law.

$$
V_{\text {out }}=\frac{R_{2}}{R_{1}+R_{2}} \cdot V_{\text {in }}
$$

where $V_{\text {in }}$ and $V_{\text {out }}$ is initial and yield voltage of the potential divider appropriately while the resistors are R1 and R2.

\subsubsection{DC-DC Boost Converter}

The dc-dc boost converter step ups the low output voltage which has gain from the solar panel as well as regulates the voltage. The output voltage of the solar panel will be the input voltage of the dc-dc boost converter. Fuzzy logic PWM signal will control the on/off time of the MOSFET switch of the DC-DC boost converter. The dc-dc boost converter acts as a charge controller where it is controlled by software based on fuzzy logic. The fuzzy logic control will track the output voltage of the solar panel and finds out the maximum power as well as controls the boost converter.

The duty cycle (D) of the MOSFET is adjusts with the fuzzy logic controller by generating the PWM signal. The voltage gets from the boost converter will be the final output voltage and it will be send to the load. The dc-dc boost converter had been designed to get a higher output voltage. The input voltage of the dc-dc boost converter will be varied from 0 to $21.5 \mathrm{~V}$; however, the maximum power point voltage of the solar panel is $18 \mathrm{~V}$ : 


$$
\frac{V_{o}}{V_{d}}=\frac{1}{1-D}
$$

where $V_{d}$ is the initial voltage, $V_{o}$ is yield voltage and duty cycle will be $\mathrm{D}$.

\subsubsection{Optocoupler}

From the controller of Arduino, the circuit of optocoupler is used as MOSFET driver to build the crest voltage, $\mathrm{Vpp}$ as signal of PWM. 5V of Vpp only can give by Arduino. On the grounds that the base exchanging voltage of the IRF830 MOSFET, the driver required in the DC-DC support converter is $10 \mathrm{~V}$ and with Vin of controller of Arduino, optocoupler can operate as far as $12 \mathrm{~V}$. Optocoupler of $4 \mathrm{~N} 25$, resistors of $10 \mathrm{k} \Omega$ and $150 \Omega$ are built in this circuit.

\section{Result and Discussions}

\subsection{Solar Tracker Mechanism}

From the controller of Arduino, the circuit of optocoupler is used as MOSFET driver to build the crest voltage, $\mathrm{Vpp}$ as signal of PWM. 5V of Vpp only can give by Arduino. On the grounds that the base exchanging voltage of the IRF830 MOSFET, the driver required in the DC-DC support converter is $10 \mathrm{~V}$ and with $\mathrm{V}_{\text {in }}$ of controller of Arduino, optocoupler can operate as far as $12 \mathrm{~V}$. Optocoupler of $4 \mathrm{~N} 25$, resistors of $10 \mathrm{k} \Omega$ and $150 \Omega$ are built in this circuit.

\subsubsection{Dual Axis Solar Tracker without System}

Table 2. Solar Panel Voltage and Output Voltage (I)

\begin{tabular}{|c|c|c|}
\hline $\begin{array}{c}\text { Time } \\
\text { (Hour) }\end{array}$ & $\begin{array}{c}\text { Solar Panel } \\
\text { Voltage }(\mathbf{V})\end{array}$ & $\begin{array}{c}\text { Output Voltage } \\
(\mathbf{V})\end{array}$ \\
\hline $8.00 \mathrm{AM}$ & 8.55 & 8.55 \\
\hline $9.00 \mathrm{AM}$ & 9.57 & 9.57 \\
\hline $10.00 \mathrm{AM}$ & 10.20 & 10.20 \\
\hline $11.00 \mathrm{AM}$ & 10.90 & 10.90 \\
\hline $12.00 \mathrm{PM}$ & 11.78 & 11.78 \\
\hline $1.00 \mathrm{PM}$ & 13.01 & 13.01 \\
\hline $2.00 \mathrm{PM}$ & 14.15 & 14.15 \\
\hline $3.00 \mathrm{PM}$ & 14.35 & 14.35 \\
\hline $4.00 \mathrm{PM}$ & 13.90 & 13.90 \\
\hline $5.00 \mathrm{PM}$ & 12.57 & 12.57 \\
\hline $6.00 \mathrm{PM}$ & 11.27 & 11.27 \\
\hline
\end{tabular}


The table 2 shows the voltage from PV solar panel voltage and output voltage. From this data, the graph of dual axis solar tracker without system was obtained in order to analyse the results.

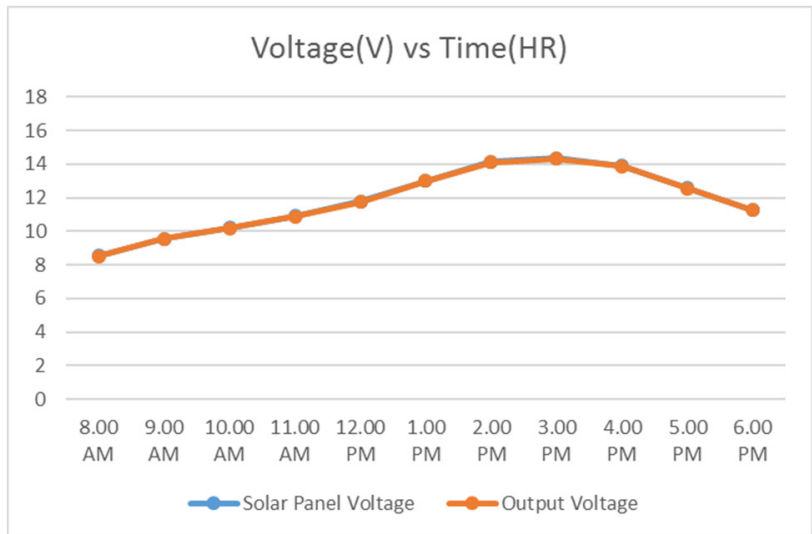

Fig. 10. Solar panel voltage and output voltage (I)

Figure 10 shows results of the experiment of output voltage and solar panel voltage against time hour. Every one hour the data shows different result in term of input voltage of a solar panel and output voltage of a battery. This happens because the solar panel receive bright sunlight ray for each one hour during experiment. At 8.00AM to 9.00AM, the input voltage starts to increase; this is because the sun light is getting brighter. The charging process runs because $10 \mathrm{~V}$ to $12 \mathrm{~V}$ DC supply was enough to flow through the charging circuit and power supply circuit. At 3.00PM, the maximum voltage input was recorded at $11.89 \mathrm{~V}$ near to the value of $12 \mathrm{~V}$.

The voltage began to increase at the peak hour starting at 10.00AM till 3.00PM. This is because there was no cloudy environment as it was cleared sky. From the peak voltage, the time that is effective for charging process was around 10.00AM to 3.00PM. However as for daily use, the same results can't be obtained because sometimes it might be cloudy or raining depends on the weather and sky conditions. Another thing that can affect the sun light ray from passing to earth is cloud which sometime blocks the sun light. As per experiment, the voltage drops slightly and not stable for the output voltage.

\subsubsection{Dual Axis Solar Tracker with System}

Table 3. Solar Panel Voltage and Output Voltage (II)

\begin{tabular}{|c|c|c|}
\hline $\begin{array}{c}\text { Time } \\
\text { (Hour) }\end{array}$ & $\begin{array}{c}\text { Solar Panel } \\
\text { Voltage (V) }\end{array}$ & $\begin{array}{c}\text { Output Voltage } \\
(\mathbf{V})\end{array}$ \\
\hline $8.00 \mathrm{AM}$ & 8.45 & 18 \\
\hline $9.00 \mathrm{AM}$ & 9.97 & 18 \\
\hline $10.00 \mathrm{AM}$ & 10.15 & 18 \\
\hline $11.00 \mathrm{AM}$ & 11.65 & 18 \\
\hline $12.00 \mathrm{PM}$ & 12.42 & 18 \\
\hline $1.00 \mathrm{PM}$ & 13.01 & 18 \\
\hline $2.00 \mathrm{PM}$ & 13.97 & 18 \\
\hline $3.00 \mathrm{PM}$ & 14.35 & 18 \\
\hline
\end{tabular}




\begin{tabular}{|l|l|l|}
\hline $4.00 \mathrm{PM}$ & 14.15 & 18 \\
\hline $5.00 \mathrm{PM}$ & 13.95 & 18 \\
\hline $6.00 \mathrm{PM}$ & 12.39 & 18 \\
\hline
\end{tabular}

The table 3 shows the voltage from PV solar panel voltage and output voltage. From this data, the graph of dual axis solar tracker with system was obtained in order to analyse the results.

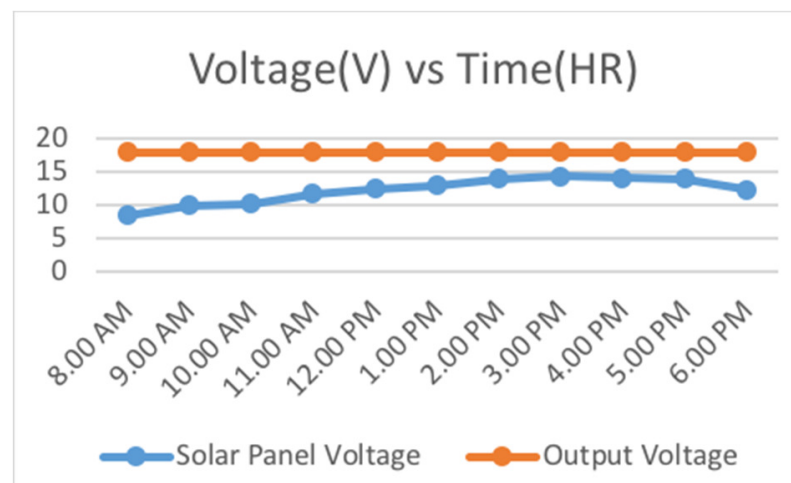

Fig. 11. Solar panel voltage and output voltage (II).

The dual axis solar tracker with system gives the maximum and stable output voltage that a solar panel does. This shown that the solar panel in this system works at full efficiency. Eventhough the weather and sky conditions affects the solar rays, the output voltage always reach $18 \mathrm{~V}$ and stable with FLC and DC-DC boost converter.

\subsubsection{Comparison for Output Voltage of with and without System}

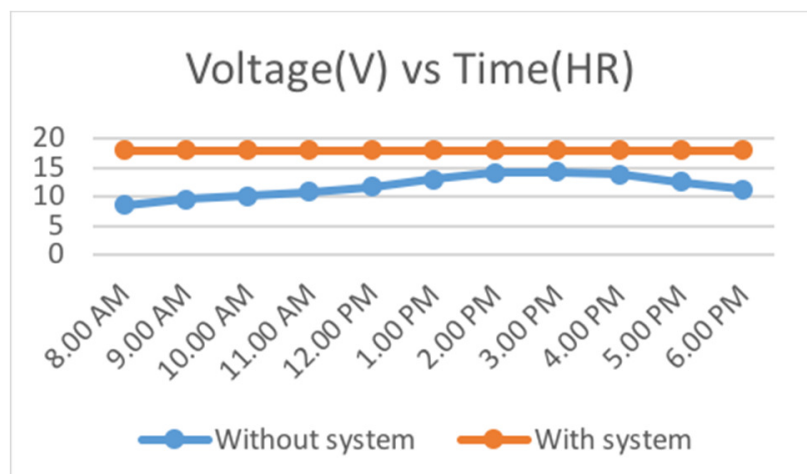

Fig. 12. Comparison of output voltage of with and without system.

Figure 12, shows the output voltage of both with and without system against time for each one hour. Output voltage for dual axis solar tracker with system constantly increase and stable compared to the dual axis solar tracker without system during daylight.

\subsection{Fuzzy Logic Controller with Output}

Table 4 demonstrates the information gathered from the controller of Arduino Uno utilizing the Power Supply of DC for the information voltage supplied the sunlight based board and also DSO to demonstrate the PWM reaction with the estimation of obligation cycle. This 
strategy has been directed to check the fluffy rationale coding or program. The duty cycle had changed by estimation of error and change of error.

Table 4. Using fuzzy logic coding and controller to collect data.

\begin{tabular}{|c|c|c|c|c|}
\hline$V_{p v}(\mathrm{~V})$ & $V_{r e f}(\mathrm{~V})$ & Error & Change of Error & $\begin{array}{c}\text { Duty cycle Digital Value } \\
(\mathbf{0}-255)\end{array}$ \\
\hline 9.40 & 18 & 0.48 & 0.48 & 220 \\
\hline 14.05 & 18 & 0.22 & -0.26 & 96 \\
\hline 7.40 & 18 & 0.59 & 0.37 & 205 \\
\hline 3.65 & 18 & 0.80 & 0.21 & 254 \\
\hline 20.00 & 18 & -0.11 & -0.91 & 0 \\
\hline 20.00 & 18 & -0.11 & 0.00 & 127 \\
\hline 16.95 & 18 & 0.06 & 0.17 & 136 \\
\hline 13.05 & 18 & 0.28 & 0.22 & 150 \\
\hline
\end{tabular}

In a DSO, the Arduino Uno caught PWM yield signal. As declare some time recently, the duty cycle had fluctuated by error and change of error of the fluffy rationale while from the controller, the PWM reactions were varied by duty cycle.

\section{Conclusion}

Definitively, the targets of this anticipate were accomplished. The model of the ideal sun based cell execution utilizing dc-dc help converter controlled by fluffy rationale controller was effectively outlined and created. The model can be used to enhance the productivity of the sun powered board.

The framework consists of three primary parts which are sun powered board, DC-DC help converter and fluffy rationale controller. The controller can control the obligation cycle of the PWM signal also deliver to MOSFET. Also, the support converter can manage the potential difference of sun powered board as per MOSFET signal. Overall, the prototype had optimised the efficiency of solar panel. The tracking system can be installed with DC to AC inverter where it can convert the DC current to AC current and electrical appliances. The battery should be replaced with the battery which has larger capacity and power for more efficiency.

The authors would like to be thanks Universiti Malaysia Pahang for providing laboratory facilities and guidance from lecturers, staffs and friends.

\section{References}

1. Khan, S. A., and Hossain, M. I., Design and implementation of microcontroller based fuzzy logic control for maximum power point tracking of a photovoltaic system. In International Conference on Electrical \& Computer Engineering (ICECE 2010), pp. 322-325 (2010)

2. Batayneh, W., Owais, A., and Nairoukh, M., Automat. Constr., 29, 100-106 (2013)

3. Ibrahim, H. E. A., and Ibrahim, M., J. Energy Technol. Policy, 2, pp. 1-12 (2012)

4. Hamed, B. M., and El-moghany, M. S., Int. J. Adv. Res. Artif. (IJARAI 2012) 1, pp. 14 21 (2012)

5. Bawa, D., and Patil, C. Y. (2013), Int. J. Eng. Innov. Technol. (IJEIT 2013), 2, pp. 179 187 (2013)

6. Pradeep, K. P. J., Reddy, K. S. P., Mouli, C. C., and Raju, K. N, Int. J. Eng. Trends Technol. (IJETT 2014), 17, pp. 3-6 (2014)

7. Afiqah Zainal, N., and Ganaisan, S. A., Appl. Mech. Mater., 793, pp. 378-382 (2015) 